\title{
SCALING AGILE FRAMEWORKS VS. TRADITIONAL PROJECT PORTFOLIO MANAGEMENT: COMPARISON AND ANALYSIS
}

\author{
Andreas Grundler and Markus Westner \\ Faculty of Computer Science \& Mathematics, Pruefeninger Str. 58, 93049 OTH Regensburg, Germany
}

\begin{abstract}
Practitioners have developed numerous frameworks around scaling agile and lean methods. These frameworks are more frequently being used in practice in large-scale system development activities. Therefore, they are in the scope of project portfolio management. The paper examines the conformity of selected scaling agile frameworks to the objectives of project portfolio management through qualitative analysis. Four prominent frameworks are investigated: Scrum of Scrums, Large Scale Scrum, Disciplined Agile, and the Scaled Agile Framework. The study shows significant differences between the frameworks and their view on project portfolio management with the Scaled Agile Framework offering the most detailed portfolio management-relevant processes and roles. In contrast to that, Large Scale Scrum does not see the need for portfolio management but promotes self-managing teams. Two of the four frameworks share the perception shift from projects to the products, which has significant implications for practitioners because it challenges and redefines prevalent management roles and practices.
\end{abstract}

\section{KEYWORDS}

Project Portfolio Management, PPM, Scaling Agile Frameworks, Agile at Large

\section{INTRODUCTION}

Today's turbulent business and technology environment increases the risk of disruption of products, services, and markets. Organizations increasingly find themselves in competitive "high-pressure" situations (Downes and Nunes, 2013). There is a higher demand for innovation and efficiency in value delivery and organizations must be able to react to changing environments and situations to be successful (Lee and Xia, 2010).

In this setting, agile methods like Scrum and Kanban increasingly gained practical relevance. According to a practitioner survey by VersionOne Inc. (2017), 94\% of over 1.000 respondents use agile development practices. The anticipated benefits of adopting agile are manifold, including the ability to manage changing priorities, to enhance project visibility, to increase team productivity and team morale, as well as to decrease time to market. Komus and Kuberg (2017) come to comparable findings: 88\% of their 902 respondents use agile methods, mentioning similar benefits.

When companies use agile methods in the context of large project portfolios, new challenges occur. Exemplary issues are synchronization of teams through multiple daily meetings and the integration of agile practices into top-down management and governance structures without sacrificing agility (Boehm and Turner, 2005). Scaling agile frameworks aim at addressing these challenges and aim at introducing agile principles and practices in large-scale settings (Eklund, Holmström Olsson, and Strøm, 2014). They scale up by increasing the number of teams and introducing coordinating and planning mechanisms (Eklund et al., 2014). By doing so, they get into the scope of project portfolio management (PPM) which aims at allocating and managing scarce company resources for high-priority initiatives, mostly in mid- to large-sized organizations (Reyck et al., 2005). Therefore, the question arises how scaling agile frameworks compare to the objectives of PPM.

In recent years, practitioners have developed numerous scaling agile frameworks. Uludag, Kleehaus, Xu, and Matthes (2017) have identified 20 frameworks in their literature review. The most cited and practical relevant frameworks are Scrum of Scrums, Large Scale Scrum, Disciplined Agile, and the Scaled Agile Framework. Practitioner surveys support this perspective (Komus and Kuberg, 2017; VersionOne Inc., 2017). 
Thus, this paper's scope are these four frameworks. The paper describes, analyzes, and compares the four frameworks in the context of PPM. It addresses the following research questions:

RQ1: What are the conceptual differences between scaling agile frameworks?

RQ2: How do scaling agile frameworks conform to the objectives of traditional PPM?

The answer to RQ1 will provide a condensed overview, description, and an understanding of the differences regarding the scope and scaling of each framework. RQ2 is highly relevant to practitioners because the approaches suggested by scaling agile frameworks in the context of large project portfolios might have a potential impact on current portfolio and project management practices and roles.

To answer the stated research questions, the paper at hand investigates the selected scaling agile frameworks in detail based on their published specifications. For each framework, underlying characteristics and concepts are outlined - answering research questions RQ1. To answer RQ2, relevant literature on PPM in the field of project management is reviewed to identify the objectives of PPM. The paper then evaluates portfolio-relevant practices against the identified objectives of PPM. For each framework, there is a summary of the evaluation in tabular form, including a conformity-rating, the level of operationalization, and the hierarchy level of the executing organizational entity (role, level) fulfilling the particular objective. The conformity rating is based on three degrees of fulfillment as described in Table 1.

Table 1. Conformity Rating Guideline

\begin{tabular}{lll}
\hline \hline Symbol & Descriptor & Decision Criteria \\
\hline & Fulfilled & Fulfillment of the objective by portfolio management or a similar management body \\
\hline & Partly fulfilled & Partial fulfillment of the objective or fulfillment by a different organizational entity \\
\hline
\end{tabular}

\section{OBJECTIVES OF PROJECT PORTFOLIO MANAGEMENT}

PPM originated from the financial industry, where portfolios of investments must be managed efficiently and effectively. Its primary goal is to maximize the overall investment portfolio return (Markowitz, 1952). This goal still holds in current project management literature, i.e., to strategically and operationally manage an organization's investments into projects to maximize return. To do so, PPM spans a bridge between strategy and implementation - doing the right things/projects to achieve a company's strategic objectives. (Reyck et al., 2005)

Beringer, Jonas, and Kock (2013) divide the objectives of PPM into three categories: Portfolio structuring, portfolio steering, and resource management. For the analysis of the four scaling agile methods in the scope of this paper, we follow their structure.

(1) Portfolio structuring's principal objective is to strategically align vast project landscapes on a periodic basis (Beringer et al., 2013). The PPM process must enable selection and prioritization of projects to be undertaken in the future (Gareis and Huemann, 2007; Kaiser, El Arbi, and Ahlemann, 2015; Reyck et al., 2005). Evaluation criteria for portfolio structuring in this paper will, therefore, be (1.1) Project selection and prioritization based on strategy and (1.2) Periodic reevaluation of the structure.

(2) Portfolio steering aims at continuously improving the flexibility for adjusting a portfolio to meet internal and external changes during a planning period (Beringer et al., 2013). There must be a centralized view of all projects within a portfolio to enable its analysis and steering (Reyck et al., 2005). Evaluation criteria for portfolio steering in this paper will, therefore, be (2.1) Continuous monitoring of the portfolio through a centralized view and (2.2) Re-adjusting the portfolio in case of deviations.

(3) Resource management should efficiently and effectively manage resources across the portfolio and is an initial but also continuous task (Beringer et al., 2013). Resources are allocated and re-allocated to and between projects based on prioritization (Blichfeldt and Eskerod, 2008). Constraints on shared resources must be incorporated (Reyck et al., 2005). Resource Management should also facilitate learning across projects to ensure improvement and skill development (Gareis and Huemann, 2007). Evaluation criteria for resource management in this paper will, therefore, be (3.1) Resource planning across the portfolio, (3.2) Reactive allocation of resources, and (3.3) Organizing learning of and between projects and individuals. 


\section{ANALYSIS OF THE SCALING AGILE FRAMEWORKS}

\subsection{Scrum of Scrums}

\subsubsection{Overview}

Scrum of Scrums is one of the most popular scaling frameworks according to surveys of Komus and Kuberg (2017) and VersionOne Inc. (2017). The name of the framework simultaneously describes a virtual team called "Scrum of Scrums" in the framework. This virtual team consists of one representative of each Scrum team of up to nine members.

The members of a Scrum of Scrums team cooperate to coordinate, integrate, and deliver products to the customer. Every virtual team instance operates similarly to Scrum at the team level, with communication paths being limited as only the team representatives take part in the higher-level Scrum of Scrums. Through this concept, information is communicated as effectively as possible. Representatives of Scrum of Scrums teams can also be part in higher level Scrum of Scrums teams. The depth of Scrums is not limited. For example, there can be a Scrum of Scrums of Scrums. (Scrum Inc., 2017)

Scrum of Scrums' Stand-Up Meetings take place daily after the teams' Stand-Ups with each team's representative as described above. If there are no solutions for possible impediments, issues are raised to the higher level Scrum of Scrums teams. (Scrum Inc., 2017) If impediments cannot be solved in the respective Scrum of Scrums' Stand-Ups or higher-level Scrum of Scrums teams, they are forwarded to an additional entity: The Executive Action Team, which consists of top-level executives. The Executive Action Team can be considered the highest-level Scrum team and is responsible for aligning the organization to a common transformational strategy. Besides transformational aspects, its responsibility is to remove impediments that block performance and specify Epics, i.e., large initiatives, for implementation. The specified Epics are forwarded to the Product Owners. For scaling the role of the Product Owner, there is Meta-Scrum as an additional scaling mechanism. The Product Owners work together with stakeholders and leadership, providing a stakeholder-aligned Product Backlog for the individual Scrum- or virtual Scrum of Scrums' teams. Additionally, they manage and coordinate Epics, which are too extensive to be implemented by a single Scrum team. In contrast to the sprint logic at the team level, the Meta-Scrum can be executed ad-hoc or on a recurring basis. There is no fixed cadence. (Scrum Inc., 2017).

\subsubsection{Role of Project Portfolio Management}

Scrum of Scrums is described to "remove the waste introduced into many Scrum implementations that distort Scrum and make it less agile by increasing communication pathways" (Scrum Inc., 2017). Scrum of Scrums is a minimalistic framework. It hardly introduces or addresses PPM-relevant aspects, which the following evaluation shows.

\subsubsection{Evaluation}

Portfolio Structuring: Scrum of Scrums does not contribute to aligning vast project landscapes. Although the Enterprise Action Team should select Epics for implementation as described above, Scrum of Scrums does not specify how the Epics are selected, prioritized, or aligned with the business strategy.

Portfolio Steering and Resource Management: Scrum of Scrums does not conform to the goals of PPM: It does not define or provide a centralized view on the endeavors and processes for resource planning, re-allocation, and learning.

Table 2 summarizes the conformity rating for Scrum of Scrums. Only one objective is partially fulfilled: The Enterprise Action Team selects Epics. Scrum of Scrum does not introduce any further processes. 
Table 2. Scrum of Scrums PPM Evaluation

\begin{tabular}{|c|c|c|c|}
\hline Objective & Conformity & Operationalization & Hierarchy level \\
\hline \multicolumn{4}{|l|}{ Portfolio Structuring } \\
\hline Selection and prioritization & تثي: & $\begin{array}{l}\text { Selection of Epics by the } \\
\text { Enterprise Action Team }\end{array}$ & Highest level executives \\
\hline Re-evaluation & $Y$ & $\mathrm{n} / \mathrm{a}$ & $\mathrm{n} / \mathrm{a}$ \\
\hline \multicolumn{4}{|l|}{ Portfolio Steering } \\
\hline Monitoring, re-adjusting & $y$ & $\mathrm{n} / \mathrm{a}$ & $\mathrm{n} / \mathrm{a}$ \\
\hline \multicolumn{4}{|l|}{ Resource Management } \\
\hline $\begin{array}{l}\text { Resource planning, reactive } \\
\text { allocation, organizing learning }\end{array}$ & & $\mathrm{n} / \mathrm{a}$ & $\mathrm{n} / \mathrm{a}$ \\
\hline
\end{tabular}

Scrum of Scrums can be described as a basic mechanism for scaling Scrum, enriched by further aspects like Meta-Scrum and the Executive Action Team. It could be interesting for smaller organizations in the process of transforming from traditional to agile methods, where size and scope of initiatives require the inclusion of multiple teams and the management of interdependencies and communication between them. When applying Scrum of Scrums in larger scale settings, the number of Scrum of Scrums could eventually become an issue because of the increased coordination efforts through additional Scrum of Scrums' meetings.

\subsection{Large Scale Scrum}

\subsubsection{Overview}

Large Scale Scrum (LeSS) "is Scrum applied to many teams working together on one product" (Larman and Vodde, 2016, p. 6). An organization implementing LeSS should be organized around its product(s) in a minimalistic way. Lead by the Head of Product the individual teams are on one hierarchical level with the product owner. There is no functional organization, project/program organization or project/program management. Furthermore, there are no supporting units like configuration management, continuous integration, or quality management. LeSS instead introduces a cross-functional line organization with stable teams. Teams and product owners perform managerial and supporting tasks themselves. (Larman and Vodde, 2016).

LeSS is based on an extended form of Scrum sprints consisting of the following steps: Sprint Planning 1, Sprint Planning 2, Sprint Review, and Overall Retrospective. Fundamental for a LeSS Sprint is a workshop called product backlog refinement, where "teams clarify upcoming items with users and stakeholders, split big items and (re-)estimate items" (Larman and Vodde, 2016, p. 249).

\subsubsection{Role of Portfolio Management}

An essential characteristic of LeSS is the concept of self-managing teams, which are embedded in the minimalistic organizational structure as stated before. The shift from manager-lead teams to self-managing teams has significant implications. The teams' responsibilities are "extended to include managing and monitoring process and progress. These responsibilities are removed from the manager's responsibilities" (Larman and Vodde, 2016, p. 113). Teams validate if they are on track and re-adjust themselves in case of deviations. They decide how to work, experience feedback and improve. Teams also resolve conflicts themselves and fix problems in the teams. (Larman and Vodde, 2016).

LeSS explicitly sees no necessity for a centralized PPM process. A key principle of LeSS is doing "more with less." The framework intends to replace rigid and bureaucratic PPM structures. Instead of PPM, LeSS uses one product backlog and one product owner for a whole product. The product owner is responsible for setting the goals, changes in direction, and the backlog prioritization before Sprint Planning. (Grgić, 2015)

\subsubsection{Evaluation}

Portfolio Structuring: Although LeSS denies the need for projects and PPM, initiatives are nevertheless selected and prioritized. LeSS assigns these tasks to the product owner, managing a central product backlog for the whole product, and setting its future direction. The prioritized backlog serves as an input for Sprint 
Planning. Therefore, the critical objective of PPM is fulfilled but not in a centralized management body. The organization's backlog is re-evaluated by the product owner at least every sprint which leads to a partially fulfilled rating for re-evaluation.

Portfolio Steering: LeSS does not introduce a centralized view for monitoring initiatives. Monitoring progress is part of each team's responsibility. If the teams are not on track, they readjust themselves. LeSS does not establish a centralized view for monitoring all initiatives. Therefore, this objective is not fulfilled. The iterative setup of the LeSS Sprint provides the opportunity for frequent adjustments to changing environments with the product owner adjusting the backlog constantly.

Resource Management: LeSS follows the concept of stable teams. Resources are allocated for the next LeSS Sprint, where work items are pulled from the product backlog in Sprint Planning 1. No further resource planning processes are defined. The concept of stable teams would also not re-allocate resources. For organizing knowledge transfer, LeSS proposes retrospectives where improvement experiments are set for the next sprint. There is also no centralized function organizing learning.

Table 3 summarizes the conformity rating for LeSS. The framework neglects the concept of a central project management office or PPM. Nevertheless, LeSS fulfills many objectives of PPM operationalized via product backlogs under the responsibility of the team and the product owner.

Table 3. LeSS PPM Evaluation

\begin{tabular}{|c|c|c|c|}
\hline Objective & Conformity & Operationalization & Hierarchy level \\
\hline \multicolumn{4}{|l|}{ Portfolio Structuring } \\
\hline Selection and prioritization & ثم:ثي: & $\begin{array}{l}\text { - Selection by the product owner } \\
\text { - Prioritization in the product backlog }\end{array}$ & - Product management \\
\hline Re-evaluation & 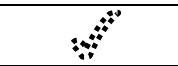 & - Review of the direction every sprint & - Product management \\
\hline \multicolumn{4}{|l|}{ Portfolio Steering } \\
\hline Monitoring & & - No centralized view & - Team tracks progress \\
\hline Re-Adjusting & 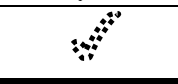 & $\begin{array}{l}\text { - Readjustment of the overall product } \\
\text { backlog every LeSS Sprint }\end{array}$ & - Product management \\
\hline \multicolumn{4}{|l|}{ Resource Management } \\
\hline Resource planning & "艹 & $\begin{array}{l}\text { - Short-term resource planning via } \\
\text { Sprint Planning } 1 \text { and } 2 \\
\text { - No mid- or long-term planning }\end{array}$ & $\begin{array}{l}\text { - Product management } \\
\text { - Teams }\end{array}$ \\
\hline Reactive allocation & 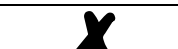 & - Stable teams of teams & $\mathrm{n} / \mathrm{a}$ \\
\hline Organizing learning & ثبثي. & - Team- and overall retrospective & $\begin{array}{l}\text { - Product Management } \\
\text { - Team }\end{array}$ \\
\hline
\end{tabular}

LeSS is scaling Scrum for more than one team, using single team Scrum practices (e.g., backlog refinement, sprints, retrospective) for multiple teams. Self-managing teams take over tasks from middle management, which probably implies a significant change effort in traditional line organizations. The denial of PPM may not be suitable for all organizations - especially those with demanding stakeholders or complex regulatory requirements. They would need at least some degree of certainty through upfront planning which is an aspect that is entirely disregarded by LeSS.

As a basis for implementing the framework, employees must be ready to take responsibility and managers simultaneously willing to give up responsibility. The framework seems to be suitable for organizations having implemented agile practices including an agile mindset and aiming for extending the practices to their whole product/service range.

\subsection{Disciplined Agile}

\subsubsection{Overview}

The Disciplined Agile (DA) Framework is developed based upon Disciplined Agile Delivery (DAD) in its version 1.x. The focus is on describing how agile/lean development teams deliver solutions using different forms of an end-to-end delivery lifecycle. DAD defines itself as a "people-first, learning-oriented hybrid agile 
approach to IT solution delivery. It has a risk-value delivery lifecycle, is goal-driven, is enterprise aware, and is scalable." (Ambler and Lines, 2016a, p. 4)

The focus of DA 2.x is on "describing a flexible, context-sensitive approach to the entire IT process" (Ambler and Lines, 2016b, p. 3). It extends DAD, to cover three main areas: DAD, Disciplined DevOps (extending DAD), and Disciplined Agile IT (extending DAD and Disciplined DevOps).

An essential characteristic of DA is that it is not prescriptive: For each of these three areas, voluntary guidelines are provided (Ambler and Lines, 2016b). The high-level DAD delivery lifecycle is as follows: The product/service runs through a lifecycle that includes five phases: From the initial concept, through the delivery phases (inception, construction, transition) to production.

For the delivery phases, DAD supports four different sub-lifecycles to build and deliver a consumable solution over time: Agile/basic (based on Scrum), Lean/advanced (based on Kanban), Exploratory (based on Lean Startup), and Continuous Delivery. Delivery teams may choose and adopt the appropriate sub-lifecycle based upon and to the individual situation. (Ambler and Lines, 2016b)

The authors point out that they do not prescribe a one-size-fits-all lifecycle, because aspects like analysis, design, architecture, programming, and testing are context dependent (Ambler and Lines, 2016a).

For every goal in the three main areas of the DA framework (DAD, Disciplined DevOps, Disciplined Agile IT), process areas with options as guidelines are described. They are called "Process Blades," which are defined as interconnected components in the organization where changes in one area are probably affecting other areas. For the Process Blades, DA describes process goals representing processes like the construction phase of the delivery lifecycle (DAD), Release Management (Disciplined DevOps) or Portfolio Management (Disciplined Agile IT). (Ambler and Lines, 2016b)

A Process Goal Notation describes each process goal: It defines decision points with a list of options and possible starting points. Decision points are tasks that should be fulfilled within the process - like the prioritization of possible initiatives in a portfolio. The lists of options are ordered or unordered. If the options are ordered, the most desirable option is on top of the list.

\subsubsection{Role of Project Portfolio Management}

DA describes PPM as one of the previously introduced Process Blades and belongs to the Disciplined Agile IT area of the framework. It "addresses how an IT organization goes about identifying, prioritizing, organizing and governing their various IT endeavors" (Ambler, 2017). Following the definition of a Process Blade, DA portfolio management is linked to other Process Blades in the framework: Looking at Disciplined Agile IT, portfolio management gets input from enterprise architecture (technology roadmap), product management (business roadmap, priorities) and IT governance (guidance for metrics, roles, and responsibilities). It has a two-way connection to continuous improvement - providing and receiving improvement suggestions. Regarding Disciplined DevOps, portfolio management gets input from the Process Blades release management, operations, support, and data management (operations intelligence). Regarding DAD, portfolio management receives feedback from teams and programs (development intelligence) and provides initial team funding, vision, and guidance. (Ambler, 2017)

As a basis for enabling efficient portfolio management, DA describes a mindset including 13 agile philosophies. For the portfolio management process goal, the authors propose nine process factors specified by the previously mentioned Process Goal Notation. The nine process factors reflect some of the mindset's 13 agile philosophies.

\subsubsection{Evaluation}

Portfolio Structuring: Regarding portfolio structuring, the process factors number 1-3 from DA describe selection and prioritization of initiatives: Identify potential value, explore possible endeavors and prioritize possible endeavors. The three factors can be characterized as operationalized with their containing guidelines. Nevertheless, they are expressed imprecisely at a very high level. For each factor, DA proposes options but does not explain when to use a particular approach. Although the authors did not explicitly mention that there would be a strategic project selection and prioritization, portfolio management decides while considering the business roadmap and the priorities provided by the product management Process Blade. The PPM objective selection and prioritization is therefore partially fulfilled. Concerning the periodic re-evaluation of the overall portfolio structure, there are no roles, processes or guidelines proposed which leads to the objective not being fulfilled. 
Portfolio Steering: The process factor number 9 "govern the portfolio" represents the operationalization of continuous monitoring of the portfolio. There are also no detailed processes defined but only options. The portfolio management gets development intelligence from the IT delivery teams, but it is not described or prescribed, which metrics should be gathered or reported. The agile philosophy number 8 "trust but verify" briefly describes the automatic calculation of metrics: Though portfolio management should trust the teams, automatically calculated metrics (e.g., team dashboards) should be collected and provided to senior management. The objective of monitoring through a centralized view is therefore partly fulfilled. For re-adjusting the portfolio, there are no mechanisms defined.

Resource Management: For resource planning, DA describes two process factors: Finance endeavors and plan IT capability. The options provided for IT capability are only described superficially without any detail on concrete actions. Furthermore, it may not be sufficient to simply plan IT capabilities because traditional and more importantly agile product teams often include staff from the business unit and the customer. Financial resource planning is mentioned, but not operationalized. Though organizing learning is not a responsibility of portfolio management, DA proposes to organize skill development in Communities of Practice.

Furthermore, the authors describe a dedicated Process Blade for continuous improvement that proposes approaches. Portfolio management provides and receives improvement suggestions to and from this entity but is not directly responsible for it.

Table 4. DA PPM Evaluation

\begin{tabular}{|c|c|c|c|}
\hline Objective & Conformity & Operationalization & Hierarchy level \\
\hline \multicolumn{4}{|l|}{ Portfolio Structuring } \\
\hline Selection and prioritization & تثئيs: & $\begin{array}{ll}- & \text { Selection and prioritization in } \\
\text { process factors number } 1-3\end{array}$ & - Portfolio management \\
\hline Re-evaluation & 1 & $\mathrm{n} / \mathrm{a}$ & $\mathrm{n} / \mathrm{a}$ \\
\hline \multicolumn{4}{|l|}{ Portfolio Steering } \\
\hline Monitoring & مثئ. & $\begin{array}{l}\text { - Centralized view is not described } \\
\text { - Process factor govern the portfolio }\end{array}$ & - Portfolio management \\
\hline Re-adjusting & $\eta$ & $\mathrm{n} / \mathrm{a}$ & $\mathrm{n} / \mathrm{a}$ \\
\hline \multicolumn{4}{|l|}{ Resource Management } \\
\hline Resource planning & تُثي. & $\begin{array}{l}\text { - Resource planning in process } \\
\text { factors } 7,8\end{array}$ & - Portfolio management \\
\hline Reactive allocation & 8 & $\mathrm{n} / \mathrm{a}$ & $\mathrm{n} / \mathrm{a}$ \\
\hline Organizing learning & نم: & $\begin{array}{l}\text { - Guidance to and from Continuous } \\
\text { improvement } \\
\text { - Communities }\end{array}$ & $\begin{array}{l}\text { - Continuous improvement } \\
\text { Process Blade }\end{array}$ \\
\hline
\end{tabular}

Table 4 summarizes the conformity rating for DA. The framework fulfills some objectives of PPM, operationalized via the described portfolio management process factors and agile philosophies. The high-level description, which is sometimes vague, prevents it from achieving a full conformity rating. Portfolio management as the fulfilling entity is one of the introduced Process Blades of DA.

DA provides best practice approaches for delivery, DevOps and the whole IT organization. The understanding of scaling is different from the other investigated frameworks: DA enriches agile and lean methods with guidelines for situations faced in larger enterprises throughout the described Process Blades. The key principle of DA is context awareness. Ambler and Lines (2016b) argue that process-related frameworks like SAFe are too prescriptive, only appear to be attractive at first sight, and often do more harm than good within the organizations. While the authors mostly provide comprehensible content, the maturity level of the framework appears to be low in some areas: There are inconsistencies at naming (process factors, decision points) and the ordering of possible approaches is not always consistent and clearly motivated. The individual decision points are mostly vague. Additionally, the framework does not describe roles, processes, and dependencies in detail. 


\subsection{Scaled Agile Framework}

\subsubsection{Overview}

The Scaled Agile Framework (SAFe) is the most popular scaling mechanism according to surveys of Komus and Kuberg (2017) and VersionOne Inc. (2017). It is a publicly available knowledge base of integrated processes and roles for Lean-Agile development of software and systems in enterprises. It synchronizes direction, collaboration, and output for multiple agile teams. SAFe is largely based on Scrum and Kanban practices, values and principles that are applied in a scalable and modular framework to fit different sizes and structures of organizations. (Scaled Agile Inc., 2016)

Since SAFe version 4, the framework is available in four different configurations. Portfolio SAFe is being used for this paper's analysis because it includes relevant portfolio management and governance structures, processes and roles.

\subsubsection{Role of Portfolio Management}

SAFe provides unique processes and an organizational level for PPM. The portfolio level describes several key elements: Strategic Themes reflect the overall business strategy in the portfolio and serve as a basis for reporting relevant performance indicators to the enterprise. Additionally, they serve as an input for budgeting and backlogs in the portfolio and program level and support decisions within the Portfolio Kanban board. The Kanban visualizes work and introduces work-in-progress limits to implicitly monitor and steer demand and capacities in the Value Streams. The Value Streams are funded by the concept of Lean Budgets that allows for efficient decentralized decision making with appropriate financial control and accountability. Lean Portfolio Management accounts for the budget. (Scaled Agile Inc., 2017d)

The budgets are assigned to Value Streams instead of projects, which is described as a significant step, moving resource- and content-relevant decisions to the Value Stream stakeholders, who are more knowledgeable in their business domain. The framework proposes that budgets should be assigned twice a year. Both practices increase flexibility regarding the day-to-day situation in the backlog by not thoroughly planning tasks and cost upfront. To make sure that the Value Streams build the appropriate solutions, all larger initiatives (Epics) must go through the Portfolio Kanban and must Lean Portfolio Management must approve them. On a Program level, Product Management is responsible for prioritizing the Program Backlog and its Features. (Scaled Agile Inc., 2017b)

For monitoring ongoing initiatives, SAFe proposes detailed metrics for each organizational level. In analogy to the Agile Manifesto (Beck et al., 2001), the authors point out that the most important measure is the objective evaluation of the working product (e.g., in System Demos). Thus, detailed metrics are subordinate to the overarching goal of effective solution delivery. A selection of progress measures is presented as follows: On the portfolio level, the Kanban board helps to track the status of Epics going through the system - from the Funnel phase to completion. During the implementing phase, the progress towards completion can be measured and visualized using the Epic Burn-Up chart, where the actual story points are aggregated from the program level and compared against the estimate from the Lean Business Case. The Epic Progress Chart helps to compare a multiplicity of Epics. For each epic, it visualizes the initial and current estimates, the actual story points that are work in progress, and the stories that have recently been completed. (Scaled Agile Inc., 2017c).

\subsubsection{Evaluation}

Portfolio Structuring: Regarding portfolio structuring, SAFe offers specific roles and processes fulfilling the objectives of PPM. The portfolio level of SAFe organizes and funds the previously described Value Streams. The initiatives are mainly based on the enterprise's Strategic Themes (Scaled Agile Inc., 2016, p. 2). Thus, the major difference between Portfolio SAFe and PPM is the object that is funded: Value Streams instead of projects. Nonetheless, the key objective of PPM is present in Portfolio SAFe: "the portfolio aligns strategy to execution" (Scaled Agile Inc., 2017a, p. 20). The Kanban boards and backlogs on portfolio- and program level support the selection and prioritization of initiatives (Epics and Features). Dedicated roles manage them. On a portfolio level, SAFe proposes to use an Epic review and specification workshop for re-evaluating the portfolio structure on a regular basis. This leads to a full conformity rating for both objectives in the category portfolio structuring. 
Portfolio Steering: In the category portfolio steering, SAFe provides a centralized view of all ongoing initiatives using the introduced Kanban system. While the portfolio level is responsible for larger initiatives in the Portfolio Kanban, product management is responsible for the Program Kanban and the teams for their respective Team Kanban boards. The Kanban boards provide insight into progress, resource utilization, and potential bottlenecks. Also, metrics are provided for monitoring progress and assessment of portfolio health. The monitoring objective is therefore rated with full conformity. As readjustments to internal and external changes are a responsibility on the program level, SAFe partly conforms to this objective.

Resource Management: For managing resources, SAFe provides detailed processes. The portfolio level is responsible for mid-term planning of resources applying the concept of Roadmaps. Shorter-term resource management is executed at the program level. During planning, teams pull work to their respective team backlogs instead of a top-down pre-planning. The two planning mechanisms can be described as a rolling-wave approach with detailed short-term planning and high-level mid- to long-term planning (roadmaps). In combination with the work-in-progress limits of the Kanban system, resource allocation and load are steered implicitly. Long-lived stable teams and the concept of teams pulling work from a backlog on cadence should make the reactive allocation of resources obsolete, which is the only PPM objective that is not fulfilled by SAFe.

Table 5 summarizes the conformity rating for SAFe. PPM-relevant activities are mostly done on the portfolio and program level of the framework. The objectives are highly operationalized. The framework provides detailed descriptions of all processes including corresponding roles.

Table 5. SAFe PPM Evaluation

\begin{tabular}{|c|c|c|c|}
\hline Objective & Conformity & Operationalization & Hierarchy level \\
\hline \multicolumn{4}{|l|}{ Portfolio Structuring } \\
\hline Selection and prioritization & & $\begin{array}{l}\text { - Selection and prioritization in } \\
\text { portfolio Kanban and backlogs }\end{array}$ & $\begin{array}{l}\text { - Portfolio and program } \\
\text { level }\end{array}$ \\
\hline Re-evaluation & & $\begin{array}{l}\text { - Epic review and specification } \\
\text { workshop }\end{array}$ & - Portfolio level \\
\hline \multicolumn{4}{|l|}{ Portfolio Steering } \\
\hline Monitoring & & $\begin{array}{l}\text { - Kanban as centralized view } \\
\text { - Metrics }\end{array}$ & - Portfolio level for Epics \\
\hline Re-adjusting & نم: & $\begin{array}{l}\text { - Readjusting in Backlogs } \\
\text { (program and team) }\end{array}$ & - Program- and team-level \\
\hline \multicolumn{4}{|l|}{ Resource Management } \\
\hline Resource planning & & $\begin{array}{l}\text { - Roadmaps } \\
\text { - PI Planning } \\
\text { - Lean-Budgets }\end{array}$ & $\begin{array}{l}\text { - Portfolio-, program- and } \\
\text { team-level }\end{array}$ \\
\hline Reactive allocation & $\bar{\gamma}$ & - Stable teams of teams (ART) & $\mathrm{n} / \mathrm{a}$ \\
\hline Organizing learning & تمثيد & - PI as PDCA cycle of an ART & - Program level \\
\hline
\end{tabular}

SAFe provides an extensive set of agile and lean principles and roles in a complex framework. It combines many existing practices like Scrum, Extreme Programming, and Kanban, resulting in a process-heavy approach. Apart from the four available configurations, SAFe can be described as prescriptive.

The framework is not applicable in smaller settings. With the inclusion of the organizational levels portfolio, program and team, it is targeted on being embedded in larger organizations that have these structures in place. In addition to that, SAFe defines roles for units found in many traditional large enterprises (e.g., release management, support, portfolio management). Managers evaluating SAFe find their future roles in Lean Agile Leaders, which may make it more appealing to them.

According to Scaled Agile Inc. (2016), organizations implementing SAFe can expect " $20-50 \%$ increase in productivity, 30-75\% faster time to market, 50\%+ defect reduction and happier, more motivated employees" (p. 2). Although Scaled Agile Inc. has published case studies that support these figures, practitioners should keep in mind that these studies are used for commercialization and therefore may not be objective. In scientific research, these improvements have not yet been investigated. 


\section{COMPARISON OF THE FRAMEWORKS}

\subsection{Conceptual Differences and Similarities}

While all frameworks include similar structures like cross-functional and self-organizing teams, there are significant conceptual differences between the four frameworks. Scrum of Scrums enriches Scrum practices by a few mechanisms allowing teams to coordinate and deliver as a team of teams. LeSS rethinks self-organizing teams as self-managing teams, challenging current management practices and roles. Furthermore, it provides detailed processes for streamlining development from managing backlog items to learning and improving. SAFe offers the most extensive set of roles and practices with the overall Kanban system, an agile portfolio management approach and joint planning and coordinating cadence. All three frameworks include mechanisms for coordinating and aligning a multiplicity of agile development teams: Meta-Scrum (Scrum of Scrums), Sprint Planning (LeSS) and Program Increment Planning (SAFe). They mainly differ in their cadence. Scrum of Scrums would coordinate and align on demand, LeSS every Sprint and SAFe every Program Increment. DA only proposes using a common cadence as an option.

DA stands apart among the investigated frameworks, following a different conceptual approach by providing best practice guidelines for many organizational entities and four instead of one delivery lifecycle. Additionally, the lifecycles do not cover specific scaling issues (e.g., branching, coordination). With a broader scope than even SAFe it covers many important aspects but at the same time stays vague in some areas. As the authors propose, DA could be used in conjunction with other scaling frameworks like SAFe (Lines, 2015).

An outstanding fact is that LeSS and SAFe propose the renunciation of the concept of projects. LeSS suggests managing products, SAFe funding and managing Value Streams instead of projects. DA aims to manage product teams instead of project teams.

\subsection{Conformity to the Objectives of PPM}

Scrum of Scrums only provides approaches for selecting and prioritizing endeavors. LeSS defines more processes, fulfilling many objectives in the categories structuring, steering and resource management with the characteristic that the responsibility is de-centralized. The portfolio management Process Blade of DA fulfills some objectives, but it describes the proposed approaches only superficially. SAFe fulfills most objectives of PPM, offering detailed processes and roles for all defined categories. The key concept is the agile portfolio management approach including the overall Kanban system. For ongoing initiatives, it decentralizes re-adjustments due to portfolio external and internal changes to the program level.

All frameworks are biased towards decentralized decision making and less or no upfront planning. Furthermore, resource allocation moves from a push to a pull principle: Instead of allocating teams to work/projects, they pull items from a backlog for the next increment. Additionally, the frameworks provide mechanisms for improvement and learning.

Table 6 illustrates the comparison of the PPM conformity rating of the four investigated frameworks.

Table 6. PPM Conformity Comparison

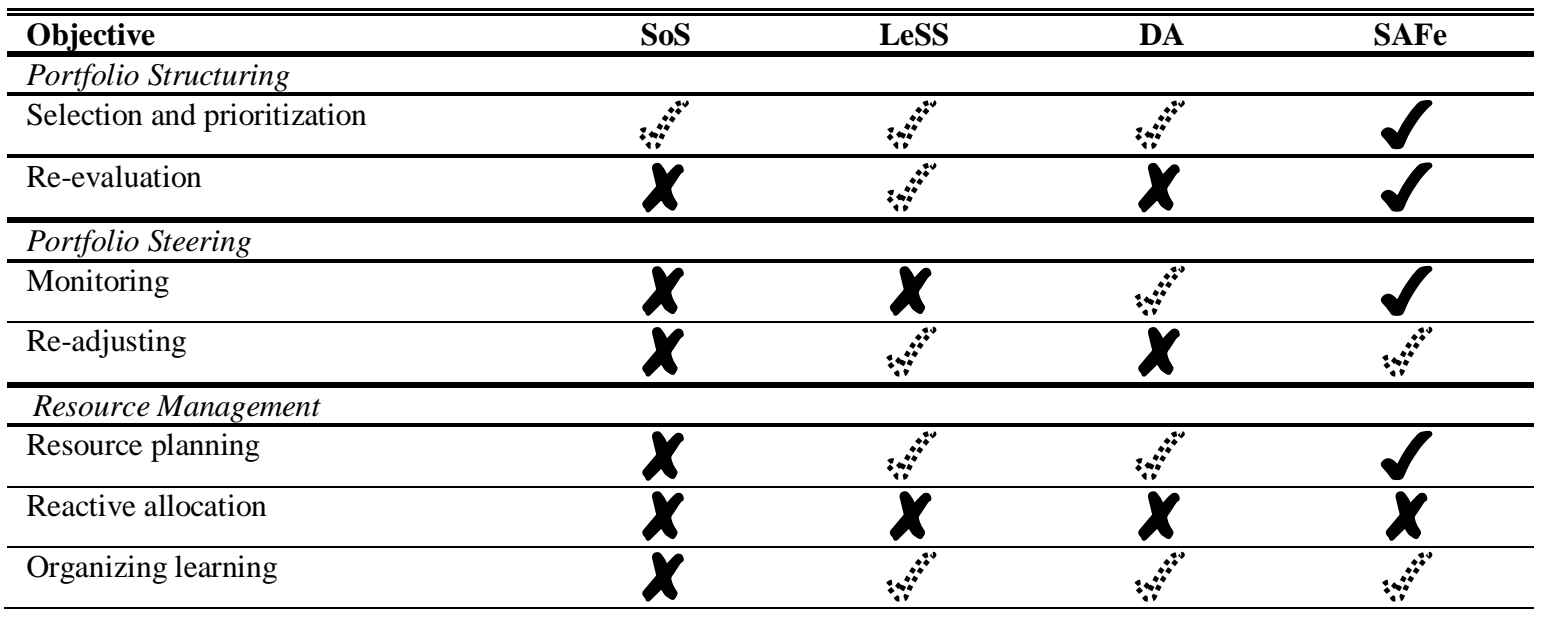




\section{CONCLUSION}

The analysis of four most relevant scaling agile frameworks from a PPM perspective showed significant differences between the frameworks. While Scrum of Scrums solely scales Scrum, LeSS scales Scrum and takes decision rights from management to product teams based on a minimalistic organizational structure around one head of product. Self-managing teams take over roles of project portfolio management and other managerial functions. DA proposes best practice guidelines for many tasks of larger enterprises. In conjunction with SAFe, both frameworks agree on having explicit portfolio management structures to be implemented. SAFe offers the most complete and detailed framework, seeming to be the best fit for large organizations which require detailed descriptions of processes and roles for their program and portfolio structures.

The critical aspect which they have in common is the shift from project to product/value-stream. This shift has significant implications on organizations: It implies the need for substantial change efforts regarding processes and mindsets as the distribution of power is decentralized. The effects could lead to strong resistances in organizations as current roles and practices are challenged.

Practitioners planning on implementing a scaling agile framework should choose carefully. The framework should be assessed concerning the organizational fit and whether the approaches are likely to solve the occurring problems and challenges. No matter which framework is going to be implemented, one should be aware that the sole implementation of scaling mechanisms is not likely to enhance the agility of the organization. True agility should be regarded as a mindset of courage and transparency, lived by managers as well as teams.

\section{REFERENCES}

Ambler, S. W. (2017). Disciplined Agile Portfolio Management. Retrieved from http://www.disciplinedagiledelivery.com/ agility-at-scale/portfolio-management/

Ambler, S. W. and Lines, M. (2016a). Scaling Agile Software Development Tactically: Disciplined Agile Delivery at Scale. Retrieved from https://disciplinedagileconsortium.org/resources/Whitepapers/Tactical\%20Agility\%20at\%20Scale.pdf

Ambler, S. W. and Lines, M. (2016b). The Disciplined Agile Process Decision Framework. In D. Winkler, S. Biffl, \& J. Bergsmann (Eds.), Lecture Notes in Business Information Processing. Software Quality. The Future of Systemsand Software Development (Vol. 238, pp. 3-14). Cham: Springer. https://doi.org/10.1007/978-3-319-27033-3_1

Beck, K., Beedle, M., van Bennekum, A., Cockburn, A., Cunningham, W., Fowler, M., ... Thomas, D. (2001). Manifesto for Agile Software Development. Retrieved from http://agilemanifesto.org/

Beringer, C., Jonas, D., and Kock, A. (2013). Behavior of Internal Stakeholders in Project Portfolio Management and its Impact on Success. In International Journal of Project Management, Vol. 31, Nr. 6, pp. 830-846. https://doi.org/10.1016/j.ijproman.2012.11.006

Blichfeldt, B. S. and Eskerod, P. (2008). Project Portfolio Management: There's More to it Than What Management Enacts. In International Journal of Project Management, Vol. 26, Nr. 4, pp. 357-365. https://doi.org/10.1016/ j.ijproman.2007.06.004

Boehm, B. and Turner, R., 2005. Management Challenges to Implementing Agile Processes in Traditional Development Organizations. In IEEE Software, Vol. 22, No. 5, pp. 30-39. https://doi.org/10.1109/MS.2005.129

Downes, L. and Nunes, P., 2013. Big Bang Disruption. In Harvard Business Review, March 2013, pp. 44-56.

Eklund, U., Holmström Olsson, H., and Strøm, N. J., 2014. Industrial Challenges of Scaling Agile in Mass-Produced

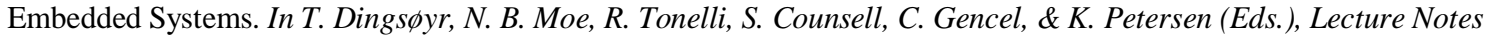
in Business Information Processing. Agile Methods. Large-Scale Development, Refactoring, Testing, and Estimation (Vol. 199, pp. 30-42). Cham: Springer. https://doi.org/10.1007/978-3-319-14358-3_4

Gareis, R. and Huemann, M. (2007). Maturity Models for the Project-Oriented Company. In R. Turner (Ed.), Gower Handbook of Project Management (4th ed., pp. 183-208). New York: Routledge.

Grgić, V. (2015). Descaling Organizations With LeSS. Retrieved from https://less.works/blog/2015/05/08/less-scalingdescaling-organizations-with-less.html

Kaiser, M. G., El Arbi, F., and Ahlemann, F. (2015). Successful Project Portfolio Management Beyond Project Selection Techniques: Understanding the Role of Structural Alignment. In International Journal of Project Management, Vol. 33, Nr. 1, pp. 126-139. https://doi.org/10.1016/j.ijproman.2014.03.002 
Komus, A. and Kuberg, M., 2017. Abschlussbericht Status Quo Agile 2016/2017: 3. Studie über Erfolg und Anwendungsformen von agilen Methoden. Retrieved from https://www.gpm-ipma.de/fileadmin/user_upload/GPM/ Know-How/Studie_Status_Quo_Agile_2017.pdf

Larman, C. and Vodde, B. (2016). Large-Scale Scrum: More with LeSS. Addison-Wesley Professional.

Lee, G. and Xia, W., 2010. Toward Agile: An Integrated Analysis of Quantitative and Qualitative Field Data on Software Development Agility. In MIS Quarterly, Vol. 34, No. 1, pp. 87-114.

Lines, M. (2015). Why Companies are Choosing DAD over SAFe. Retrieved from http://www.disciplinedagiledelivery.com/dad-over-safe/

Markowitz, H. (1952). Portfolio Selection. In Journal of Finance, Vol. 7, Nr. 1, pp. 77-91. https://doi.org/10.2307/2975974

Reyck, B. D., Grushka-Cockayne, Y., Lockett, M., Calderini, S. R., Moura, M., and Sloper, A., 2005. The Impact of Project Portfolio Management on Information Technology Projects. In International Journal of Project Management, Vol. 23, Nr. 7, pp. 524-537. https://doi.org/10.1016/j.ijproman.2005.02.003

Scaled Agile Inc. (2016). SAFe 4.0 Introduction: Overview of the Scaled Agile Framework for Lean Software and Systems Engineering. Retrieved from http://www.scaledagile.com//wp-content/uploads/delightful-downloads/2016/07/ SAFe_4_whitepaper_digital_7-16.pdf

Scaled Agile Inc. (2017a). SAFe 4.5 Introduction: Overview of the Scaled Agile Framework for Lean Enterprises. Retrieved from http://editor.scaledagile.com/wp-content/uploads/delightful-downloads/2018/01/White_Paper_SAFe-4.5.pdf

Scaled Agile Inc. (2017b). SAFe Lean Budgets. Retrieved from http://www.scaledagileframework.com/lean-budgets/

Scaled Agile Inc. (2017c). SAFe Metrics. Retrieved from http://www.scaledagileframework.com/metrics/

Scaled Agile Inc. (2017d). SAFe Portfolio Level. Retrieved from http://www.scaledagileframework.com/portfolio-level

Scrum Inc. (2017). Scrum of Scrums. Retrieved from https://www.scruminc.com/scrum-of-scrums/

Uludag, O., Kleehaus, M., Xu, X., and Matthes, F. (2017). Investigating the Role of Architects in Scaling Agile Frameworks. In 2017 IEEE 21st International Enterprise Distributed Object Computing Conference (EDOC) (pp. 123-132). IEEE. https://doi.org/10.1109/EDOC.2017.25

VersionOne Inc., 2017. The 11th Annual State of Agile Report. Retrieved from https://explore.versionone.com/state-ofagile/versionone-11th-annual-state-of-agile-report-2 